\title{
Assessment of Urban Expansion and Associated Spatial Transformation of Chandannagar City, West Bengal
}

Giyasuddin Siddique, ${ }^{\dagger}$ Subhendu Ghosh $^{+}$and Arindam Roy ${ }^{+*}$

\section{Abstract}

The Chandannagar city, as a former French colony and a historic trading centre, has witnessed a steady growth throughout the French colonial era, and the process is still in action even today. Such urban extension has altered the land use/cover (LULC) fabric both in the core and fringe areas by transforming the natural landscape. The prime goals of the study are to assess the magnitude of urban expansion of the city from 1991 to 2016 and its consequent spatial transformation by using geospatial techniques. Three indices, that is, Built-up Index (BUI), Normalised Difference Vegetation Index (NDVI) and Modified Normalised Difference Water Index (MNDWI) are employed to perceive the spatio-temporal dynamics of LULC from the remotely sensed data. Annual Growth Rate (AGR) and Land Use Integrated Index (LDI) are used to evaluate the rate, magnitude, and nature of changes. The results reveal that the rapid increase in built-up area from $7.9 \mathrm{sq} . \mathrm{Km}$. in 1991 to 14.45 sq. $\mathrm{Km}$. in 2016 has transformed nearly $51.52 \%$ of the non-forest vegetation covers and $58.18 \%$ of the water bodies of the city during the observation period.

Keywords: Built-up Index, Geospatial Techniques, Land Use/Cover, Normalised Difference Vegetation Index, Modified Normalised Difference Water Index, Urban Expansion, West Bengal, India

\footnotetext{
${ }^{\dagger}$ Department of Geography, The University of Burdwan, West Bengal

${ }^{*}$ Corresponding Author, Email: a.roy.sc@gmail.com

(C) 2020 Siddique et al. This is an Open Access article distributed under the terms of the Creative Commons Attribution License (http://creativecommons.org/licenses/by/2.0), which permits unrestricted use, distribution, and reproduction in any medium, provided the original work is properly cited.
} 


\section{Introduction}

Land areas have frequently been transformed universally by the anthropogenic intervention from the antiquity. The existence and the operations of the human society on the earth's surface considerably alter the natural landscape that has been well indicated by the dynamics of land use/cover (LULC) pattern over time (Cheruto et al., 2016). The natural attributes of land may be termed as land covers, whereas land use refers to the outcome of the complex interactions between the natural potentiality of land and physico-cultural desires of the society. Implementation of land management strategies by human agents to meet their needs has established artificial systems (like industry, agriculture, settlement, transport, etc.) replacing the natural covers of land. Such modifications attain a global concern in the recent changing environmental circumstances.

Remotely sensed images provide detailed, precise, spatio-chronological data covering large areas. High resolution, defined spectral bandwidths and accurate geo-referencing are the imperative characteristics that have amplified the essentiality of satellite data for change detection analysis. Additionally, geospatial techniques, that is, Remote Sensing (RS) and Geographic Information System (GIS) provide a new tool, easier, effective and faster than the traditional methods for detecting, analysing, mapping and modelling the nature and extent of urban expansion and associated changes. Hence, urban planners and researchers have become progressively fascinated in using such data/methods to address urban and suburban problems over the recent past. Several studies have demonstrated the utility of remotely sensed data in monitoring LULC change in urban areas by using various indices, matrixes and models (Yang and Lo, 2002; Yuan et al., 2005; Dewan et al., 2012; Wu and Zhang, 2012; Xu et al., 2019). The central aim of this study is to assess urban expansion and associated spatial transformation of Chandannagar city of West Bengal. The study begins with an overview of increased urbanisation and associated LULC change in the context of the world. This follows the description of the location of the study area and the methods employed for the study. The results are discussed in the sections following this.

\section{Urbanisation as a dominant force of LULC change: Global Context}

Although both natural and anthropogenic factors are responsible for LULC changes worldwide, human-induced modifications seem more effective. Rapid urban expansion, one of the most dominant factors, dramatically and drastically modifies the natural landscape of a space combined with diverse geographical and socio-economic factors (Thapa and Murayama, 2010). The urban sphere represents a complex amalgamation of the natural environment and man-made structures, where the later one dominates over the former one. Despite covering only $3 \%$ of the earth's land surface, urban expansion remarkably affects the natural environment both at local and global scales (Liu et al., 2014). The global urban population are estimated to reach 5 billion in 2030 due to a recent worldwide unprecedented rate of urbanisation (UNO, 2007). The proportion of urban built-up areas has almost been doubled with the rising urban population from $18 \%$ to $36 \%$ during the last quarter of the 20thcentury (Han et al., 2009). Such massive increment in urban space has rapidly transformed the physical landscape into an anthropogenic impervious establishment, which disturbs the natural systems, functioning in the atmosphere, hydrosphere, lithosphere, and ecosphere and enormously affects the sustainability of the environment, ecosystem and society (Mundia and Murayama, 2010). The acquaintance of spatial information (especially urban space) proves its utmost usefulness to contextualise the adverse outcomes of urban growth on the natural aspects. Nowadays, it has become a fundamental criterion in framing rational management policies for sustainable environmental monitoring and urban development (Fenta et al., 2017). 


\section{Regional to Local Dimensions: Brief Literature Review and the Relevance of the Study}

Since the 1990s, the relationship between urban expansion and landscape modification has gained much attention from the academicians as urbanisation induced spatial transformation has become an issue of anxiety to both developing and developed nations (Kiggundu et al., 2018). Over the past few decades, developing countries encountered urbanisation, infrastructural development and associated land transformations in or around the fertile tract, primarily due to increasing population, industrialisation, absence of apt land-use policies and recent global economic changes (Yin et al., 2011). Comparatively, the urban growth and its consequences of the large megacities of the world are widely studied (Fanan et al., 2011) whereas, the towns and small cities of the developing world, where most urban growth is expected to occur during the next quarter, fail to draw proper attention and therefore, inadequately documented (Cohen, 2004).

The Indian scenario is not an exception. The impact of urban expansion of the large metros like New Delhi (Mohan et al., 2011; Jain et al., 2016), Mumbai (Moghadam and Helbich, 2013), Gwalior (Mohapatra et al., 2014) and Hyderabad (Wakodeet al., 2013) were extensively investigated, whereas the small and medium towns almost remained unnoticed. West Bengal, one of the most urbanised states of India before independence, has accommodated nearly $31.87 \%$ of the urban population (Census of India, 2011). However, the pattern and sufferings of unplanned urban growth of those towns/cities are poorly studied or not even documented except for the Kolkata Metropolis (Bhatta, 2009; Sahana et al., 2018). Recently, Siddique and Mukherjee (2017) have shown how rapid urbanisation in the eastern blocks of Hugli District has significantly altered the rural land use pattern with a sharp decrease in net sown areas over the last decades. Nevertheless, there is a strong inadequacy of reliable and relevant documents regarding the city under review.

Though marked as an affluent agricultural region of West Bengal, the Hugli District had experienced the development of a large number of urban centres along its eastern margin, depending upon the industrial flourishment during the colonial era. The District has witnessed an expeditious urban extension and infrastructural development towards productive cropland since the 1990s. The Chandannagar city also witnesses an immense modification of the LULC mosaic over the period. The principal objective of the present study is to assess the spatio-temporal dynamics, intensity and nature of LULC changes of Chandannagar city for the past 25 years (1991-2016) with special reference to built-up spaces.

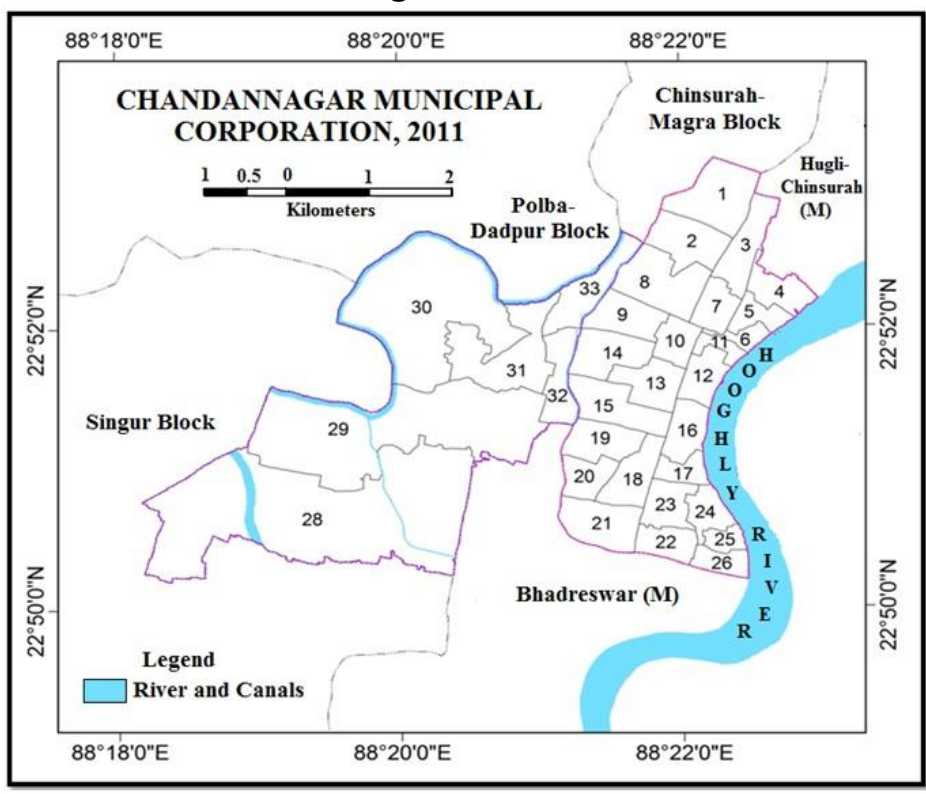

Figure 1: Location of the Study Area

Source: Prepared by the Authors based on Ward Map of CMC, 2011 


\section{Location of the Study Area}

Geographically located on the west bank of the Hooghly River, the city extends from $22^{\circ} 50^{\prime} 54^{\prime \prime} \mathrm{N}$ to $22^{\circ} 57^{\prime} 17^{\prime \prime} \mathrm{N}$ and $88^{\circ} 18^{\prime} 24^{\prime \prime}$ Eto $88^{\circ}-24^{\prime} 26^{\prime \prime} \mathrm{E}$. It covers a total geographical area of $22.03 \mathrm{sq}$. km. (Figure 1). Established in 1955, now the Chandannagar Municipal Corporation (CMC) comprises 33 wards and accommodates nearly 166867 population (Census of India, 2011). It must be noted that Ward no. 27 is excluded from the study due to its isolated location, surrounded by neighbouring Bhadreswar and Champdani Municipality that makes it an administratively handicapped spatial unit.

As a former French colony in Eastern India, the city, characterised by glorious colonial legacy and culture enjoys an esteemed position amongst the major urban units of the state. Located only $35 \mathrm{~km}$ away, the city is well connected with Kolkata, the capital city of West Bengal. Locational suitability, well rail-road connectivity and easy accessibility have influenced the daily commuters' flow that has encouraged the pace of urbanisation in the last few decades.

The urban growth of the city was initiated in 1673, centring around three localities: Khalisani, Borokishanpur and Gondalpara (Ghosh and Siddique, 2018a). Later the city has expanded horizontally over the adjoining areas through subsequent phases:

- Area before 1991 (Wards 1 to 27): The older part (core area) of the city, occupying 9.5 sq. $\mathrm{km}$. of area was the pivot of administrative and economic activities since the commencement of the French rule. Even today, almost all the commercial, institutional (academic and administrative) and maximum residential units are positioned in this part. Naturally, this part possesses a high population density compared to the newly developed portion of the city.

- Added Area of Post-1991 (Wards 28 to 33): Six new wards, comprising an area of $12.53 \mathrm{sq} . \mathrm{km}$. have been incorporated with the older part of the city on 31st
December 1994 from the jurisdiction of Khalisani Gram Panchayat.

\section{Materials and Methods}

Data Sources: The study attains its present shape through the analysis of remotely sensed data due to the lack of reliable micro-level official records. The index-based classification method is used to detect the changes for the years 1991, 1996, 2001, 2006, 2011, and 2016 (dividing the entire study period of 25 years at an interval of five years) from the imageries of Landsat 5 TM, 7 ETM+, 8 OLI and TIRS. Concurrently, relevant research articles are reviewed to construct the theoretical framework.

Change Detection Indices: Among the different vegetation indices, NDVI is extensively used to assess the chronological changes of the green health over a wide area due to its higher efficiency (Lyon et al. 1998). The algorithm subtracts the red reflectance from the nearinfrared (NIR) and divides it by the sum of the two (Tucker, 1979):

$$
N D V I=N I R-R e d / N I R+\text { Red }
$$

[For this study, a threshold of 0.20 has been set to eliminate non-vegetated areas.]

NDBI is reckoned to detect the changes in builtup space by using three bands: Red, NIR and midinfrared (MIR):

$$
N D B I=M I R-N I R / M I R+N I R
$$

Finally, the BUI is extracted by subtracting the NDVI value from the NDBI value (Zha et al. 2003):

$$
\text { BUI }=\mathbf{N D B I}-\mathbf{N D V I}
$$

MNDWI is more suitable than Normalised Difference Water Index (NDWI), developed by Mc Feeters in 1996 to extract water information from urban environs by reducing or even removing the vegetation, land and soil noise. It is computed by using the subsequent formula (Xu, 2006):

\section{MNDWI= Green-MIR/Green + MIR}

Estimation of the Dynamism: Annual growth rate (AGR) and LULC integrated index (LDI) are computed to examine the magnitude of LULC change (Haregeweyn et al. 2012): 
$\mathrm{AGR}=(U A i+n-U A i) /(n X U A i) X 100$

[UAi+n and UAi: Area at $i+n^{\text {th }}$ and $i^{\text {th }}$ year respectively, and $n$ : Time interval]

Periodical changes of LULC classes were calculated for the six subsequent periods (199196, 1996-2001, 2001-05, 2005-11 and 2011-16).

$$
L D I=100 X \sum A i X C i
$$

Where, Ai (Rate of Changes of LULC) $=\boldsymbol{U} b \boldsymbol{i} \sim \boldsymbol{U a i} / \sum(\boldsymbol{U b i} \sim \boldsymbol{U a i})$, and

Ci (LULC Change intensity Index) = Ubi $\sim \boldsymbol{U a i} /$

B

[Uai and Ubi: Area at the beginning and end of a period respectively; $B$ : Total area]

Assessment of Urban Expansion: the Speed(S) and Intensity(I) of urban growth are computed by using the following equations (Jinlong et al. 2007):

$$
\begin{gathered}
S=\Delta U i /(\Delta t X U L A i) X 100 \% \\
I=(\Delta U i X 100) /(T L A X \Delta t)
\end{gathered}
$$

[ $\triangle t$ : Time; $\triangle U r i$ : Areal expansion during the $i^{\text {th }}$ period; ULAi: Area at the beginning of the $i^{\text {th }}$ period; TLA: Total area]

Measuring the Inter-Relationships: The land consumption rate (LCR), an index to measure the progressive spatial expansion of a city concerning its population, was computed by using the following equation (Sharma et al., 2012):

\section{LCR = Built-up Area / Population}

The population statistics of 1991, 2001 and 2011 were obtained from the Census, whereas for1996, 2006 and 2016, it was projected by using the formula below:

$$
P n=P o(1+r / 100)^{n}
$$

[Pn and Po: Population size of the projected and the base year respectively, $r$ : Mean annual growth rate; $n$ : Time intervals]

Linear regression analysis $(y=a+b x)$ was employed to establish the inter-relationships between built-up space and green/ blue spaces.

Accuracy Assessment: In an image-based analysis, accuracy appraisal is obligatory to reveal the precision level or the degree of correspondence between the ground reality and the obtained results (Cheruto et al., 2016). The overall accuracy of the change detection is $83.3 \%$, which signifies the reliability of the study. Fifty pixels from each LULC category were randomly chosen. The genuine identity for half of them was verified on the ground by recording the Ground Control Points (GCPs) with the help of the Global Positioning System (GPS). The rest 25 points in each category were verified by using Google Earth Imageries.

\section{Results and Discussion}

Four LULC classes are selected for the study, that is, (i) Built-up areas (Red Space): Artificial surfaces including residential, commercial, industrial, recreational and transportation infrastructures (ii) Non-forest Vegetation cover (Green Space): Interspersed green patches including gardens and parks, roadside plantation and trees (iii) Water areas (Blue Space): Wetlands and water bodies or tanks (natural or man-made) and (iv) Wasteland (Fallow land and Open spaces). The first three classes were derived from the images, whereas the fourth includes the rest land areas to the total.

\section{Changes in Built-up Space: Speed and Intensity of Urban Expansion}

The city has experienced a continuous increase of built-up areas during the study period through gradual urban encroachment towards the adjacent areas. In 1991, only 7.9 sq. Km (35.86\%) areas were under the concrete cover, which has almost been doubled ( $14.45 \mathrm{sq} . \mathrm{km}$ or $65.59 \%$ ) in 2016 at the expense of natural land covers like water bodies, green and open spaces (Table 2). Time series analysis exhibits a very strong positive growth trend in built-up spaces $[b=$ 1.266, $\mathrm{R} 2=0.956$ ] during the stipulated phase. The urban area was expanded at a rate of $30.65 \%, 13.06 \%$. $6.61 \%, 11.90 \%$ and $3.80 \%$ in different periods of 1991-96, 1996-2001, 200106, 2006-2011 and 2011-16 respectively. The following map depicts the increment of urban space from 1991 to 2016 (Figure 2). 

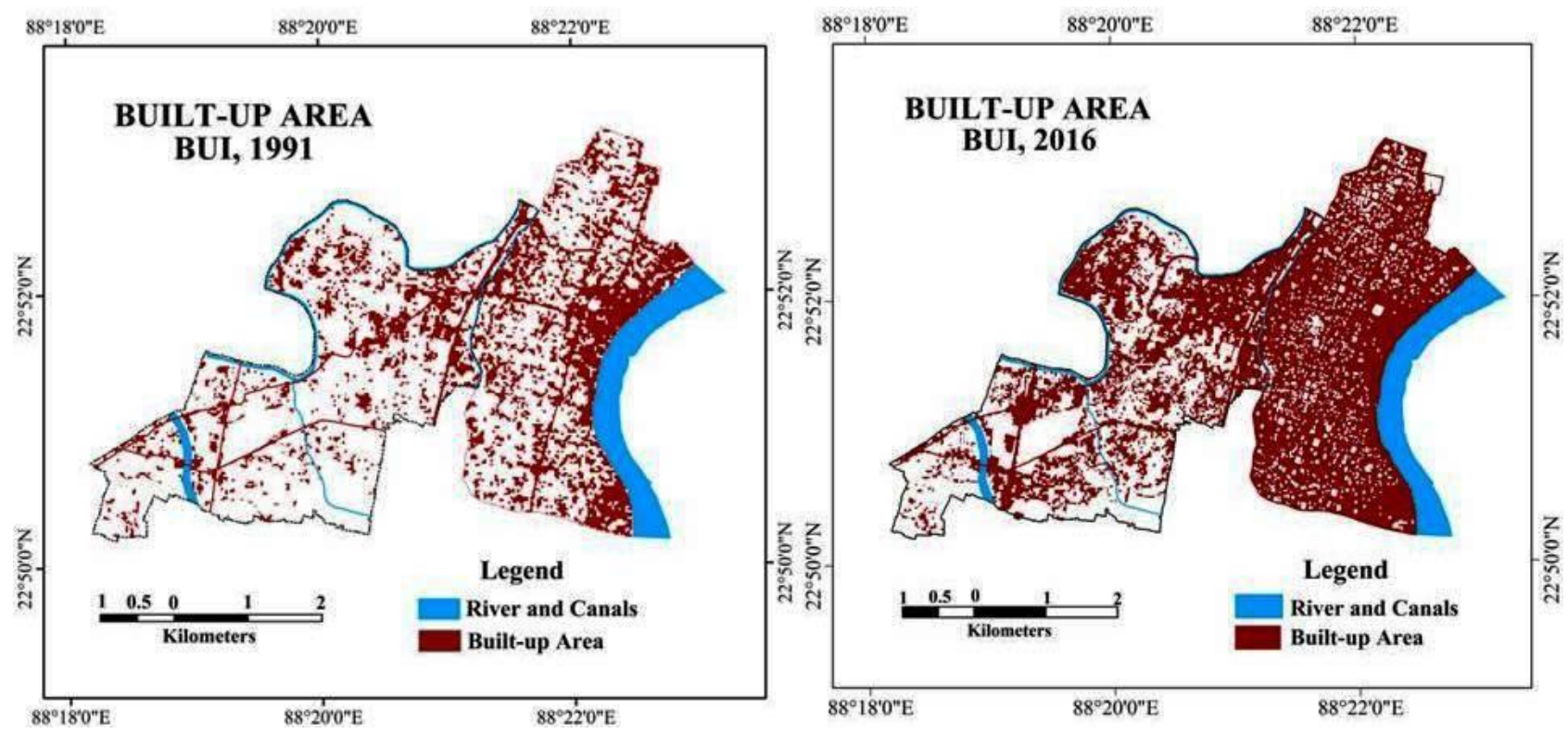

Figure 2: Change in Built-up Area, 1991 and 2016 Source: Prepared by the Authors

Highest expansion (2.42 sq. km) occurred during 1991-96 (AGR= 6.13\%) with the annexation of contiguous rural areas in 1994 as the city started to expand towards the added part along the transport routes due to the insufficiency of land in the core area (Table 4). The rate gradually $d$ windles over the subsequent periods, though it constantly remains positive. The lowest rate of increase $(0.76 \%)$ is reported during the last period (2011-16).

Urbanisation often brings some conspicuous changes in the urban structure, morphology and ecology, especially in the core areas (Ghosh and Siddique, 2018a). Besides the horizontal expansion, the city slowly grows vertically with changing housing style and structure. The building composition of the cityis changed gradually with the continuous decrease of kaccha houses and an increase in four/fivestoried buildings (Figure 3).The proportion of kaccha houses is reduced at a rate of $19.97 \%$ during the last decade (2001-11), whereas the four and five-storied buildings have increased at a rate of $31.78 \%$ and $44.19 \%$ respectively. New urban extension with modern building structure is visible briskly in the areas of Bagbazar, Borobazar, Fatokgora, Hatkhola, Lichutala, Jyoti, Mankundu, Sitalatala, Khalisani, whereasthe residents still retain their legacy of colonial culture, rituals and heritage in the areas of Haridradanga, Boxigoli and Boraichanditala along with old fashioned houses.

Table No. 1 shows the speed and intensity of urbanisation of five different periods. Maximum speed (6.13\%) and intensity (2.20) were found during the 1991-96 phase which has decreased over the periods and has reported least in the last phase due to the lack of open spaces within the city's territory.

\begin{tabular}{|c|c|c|c|c|c|c|c|c|c|c|}
\hline \multirow[b]{2}{*}{ Year } & \multicolumn{5}{|c|}{ Speed (\%) } & \multicolumn{5}{|c|}{ Intensity } \\
\hline & $\begin{array}{l}1991- \\
\text { '96 }\end{array}$ & $\begin{array}{l}1996- \\
2001\end{array}$ & $\begin{array}{l}2001- \\
\text { '06 }\end{array}$ & $\begin{array}{l}2006- \\
' 11\end{array}$ & $\begin{array}{l}2011- \\
' 16\end{array}$ & $\begin{array}{l}1991- \\
\text { '96 }\end{array}$ & $\begin{array}{l}1996- \\
2001\end{array}$ & $\begin{array}{l}\text { 2001- } \\
\text { '06 }\end{array}$ & $\begin{array}{l}2006- \\
' 11\end{array}$ & $\begin{array}{l}2011- \\
' 16\end{array}$ \\
\hline $\begin{array}{l}\text { Built- } \\
\text { up } \\
\text { Area }\end{array}$ & 6.13 & 2.62 & 1.32 & 2.13 & 0.73 & 2.20 & 1.23 & 0.70 & 1.34 & 0.48 \\
\hline
\end{tabular}




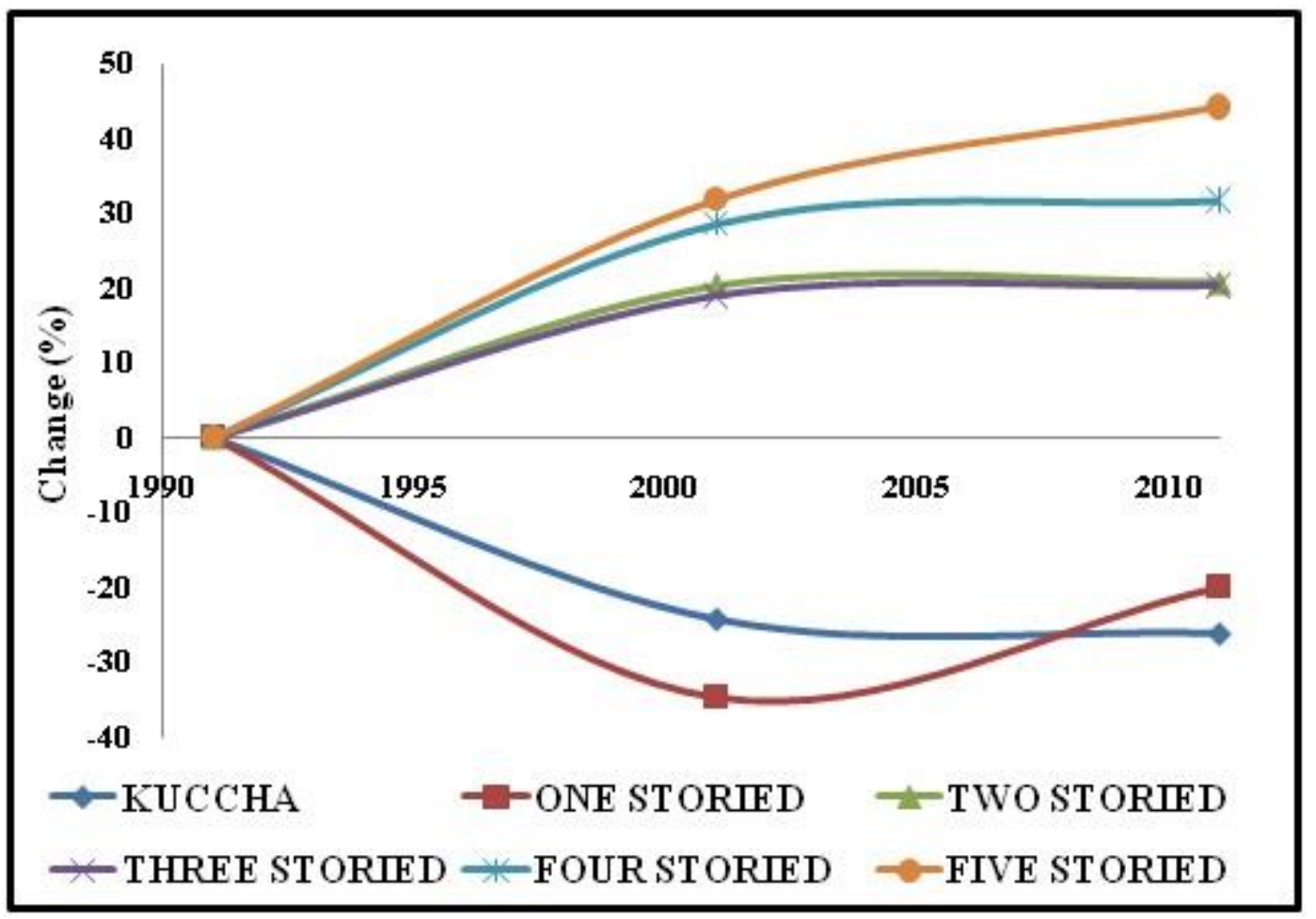

Figure 3: Changing Building Composition, 1991-2011

Source: CMC, 2011

\section{Changes in Green and Blue Spaces}

The reduction of the green cover is the most conspicuous outcome of incessant urban expansion of the city as nearly half of the green sphere has been vanished during the study period. Time series analysis reveals a very strong negative trend over the period $\left[b=-1.116, R^{2}=\right.$ $0.944]$. The green cover has been declined from 11.88 sq. km. (53.93\%) in 1991 to $6.12 \mathrm{sq} . \mathrm{km}$. (27.78\%) in 2016 through the alteration of vegetation cover into concrete areas by urban

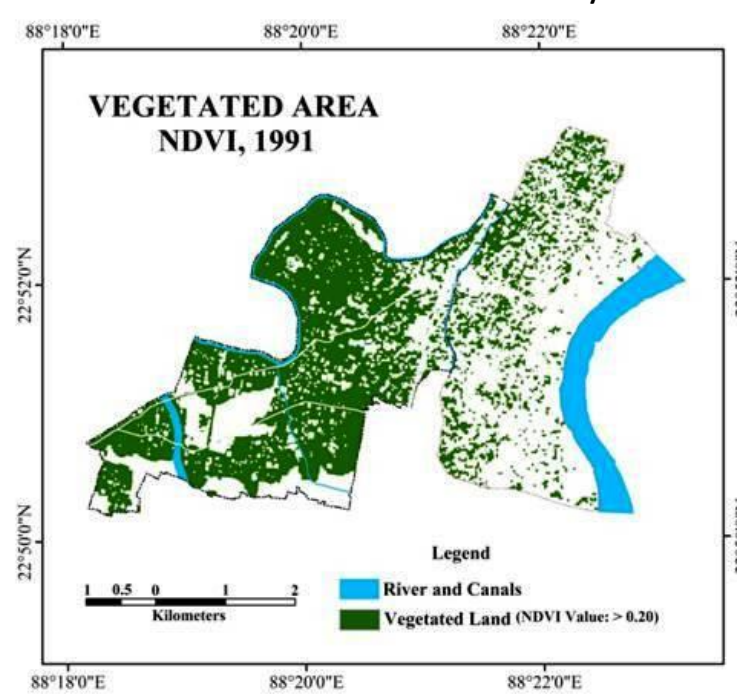

encroachment and infrastructural establishment (Tables 2 and 3). Maximum loss (10.08\%) was occurred during 1991-96 (AGR=3.74\%), whereas the minimum annual rate of shrinkage ( $A G R=$ $1.11 \%)$ was recorded during the last five years of the study (2011-16). Figure 4 portrays that the vegetated area in the older part of the city has already been utterly vanished and now the destruction process directed towards the newly annexed part at an accelerated rate with the development initiatives in those areas.

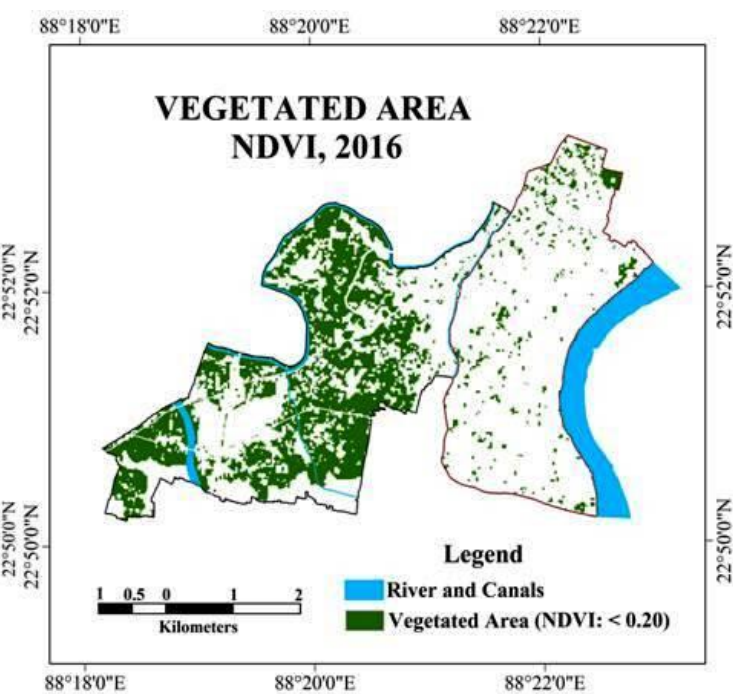

Figure 4: Change in Vegetation Cover, 1991 and 2016 Source: Prepared by the Authors 
Concurrently, the water areas of the city have continuously been abridged in a slow but steady rate as a consequence of the infilling of water bodies to meet infrastructural requisition. The blue space has been reduced from $2.2 \mathrm{sq} . \mathrm{km}$. (9.99\%) in 1991 to 1.28 sq. km. (5.81\%) in 2016. Hence, almost $4.18 \%$ of water space has been converted during the observation period (Table 3 ). Many of the surface water bodies are totally abolished and many of them are shrunk in size. Time series analysis shows a strong negative trend of loss of water bodies over the period $[b=-$ $\left.0.167, R^{2}=0.930\right]$. The annual rate of destruction of the water bodies was highest (3.73\%) during 1991-96, which has been lowered down to $1.97 \%$ during the last five years (2011-16) (Table $3)$. Figure 5 clearly shows the declining nature of water-covered areas over the study period.

\begin{tabular}{|c|c|c|c|c|c|c|c|c|}
\hline \multicolumn{9}{|c|}{ Table: 2 Trends of LULC Classes, 1991-2016 } \\
\hline \multirow[t]{2}{*}{ Year } & \multicolumn{2}{|c|}{ Built-up Areas } & \multicolumn{2}{|c|}{ Vegetation Cover } & \multicolumn{2}{|c|}{ Water Bodies } & \multicolumn{2}{|c|}{ Waste Land } \\
\hline & $\mathrm{Sq} \mathrm{Km}$ & $\%$ & $\mathrm{Sq} \mathrm{Km}$ & $\%$ & $\mathrm{Sq} \mathrm{Km}$ & $\%$ & $\mathrm{Sq} \mathrm{Km}$ & $\%$ \\
\hline 1991 & 7.9 & 35.86 & 11.88 & 53.93 & 2.2 & 9.99 & 0.05 & 0.23 \\
\hline 1996 & 10.32 & 46.85 & 9.66 & 43.85 & 1.79 & 8.13 & 0.26 & 1.18 \\
\hline 2001 & 11.67 & 52.97 & 8.41 & 38.18 & 1.68 & 7.63 & 0.27 & 1.23 \\
\hline 2006 & 12.44 & 56.47 & 7.66 & 34.77 & 1.53 & 6.95 & 0.4 & 1.82 \\
\hline 2011 & 13.92 & 63.19 & 6.48 & 29.41 & 1.42 & 6.45 & 0.21 & 0.95 \\
\hline 2016 & 14.45 & 65.59 & 6.12 & 27.78 & 1.28 & 5.81 & 0.18 & 0.82 \\
\hline$R^{2}$ & 0.956 & & 0.944 & & 0.93 & & 0.085 & \\
\hline
\end{tabular}

Table 3: Periodical Changes in LULC classes, 1991-2016

\begin{tabular}{|c|c|c|c|c|c|}
\hline \multicolumn{6}{|c|}{ Categories } \\
\hline Periods & Parameters & Built-up Area & Vegetation Cover & Water Bodies & Waste Land \\
\hline \multirow{3}{*}{ 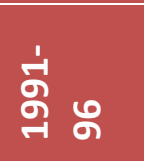 } & Area (sq km) & 2.42 & 2.22 & 0.41 & 0.21 \\
\hline & Percentage & 46.01 & 42.21 & 7.79 & 3.99 \\
\hline & Annual Rate (\%) & 6.13 & 3.74 & 3.73 & 84 \\
\hline \multirow{3}{*}{ ஓे 동 } & Area (sq km) & 1.35 & 1.25 & 0.11 & 0.01 \\
\hline & Percentage & 49.63 & 45.96 & 4.04 & 0.37 \\
\hline & Annual Rate (\%) & 2.62 & 2.59 & 1.23 & 0.77 \\
\hline \multirow{3}{*}{ 횽 } & Area (sq km) & 0.77 & 0.75 & 0.15 & 0.13 \\
\hline & Percentage & 42.78 & 41.67 & 8.33 & 7.22 \\
\hline & Annual Rate (\%) & 1.32 & 1.78 & 1.79 & 9.63 \\
\hline \multirow{3}{*}{ 용 검 } & Area (sq km) & 1.48 & 1.18 & 0.11 & 0.19 \\
\hline & Percentage & 50.00 & 39.86 & 3.72 & 6.42 \\
\hline & Annual Rate (\%) & 2.38 & 3.08 & 1.44 & 9.50 \\
\hline \multirow{3}{*}{ 릉 ம } & Area (sq km) & 0.53 & 0.36 & 0.14 & 13.21 \\
\hline & Percentage & 50.00 & 33.96 & 0.03 & 2.83 \\
\hline & Annual Rate (\%) & 0.76 & 1.11 & 1.97 & 2.86 \\
\hline \multicolumn{6}{|c|}{ Sources: Calculated by the Authors } \\
\hline
\end{tabular}



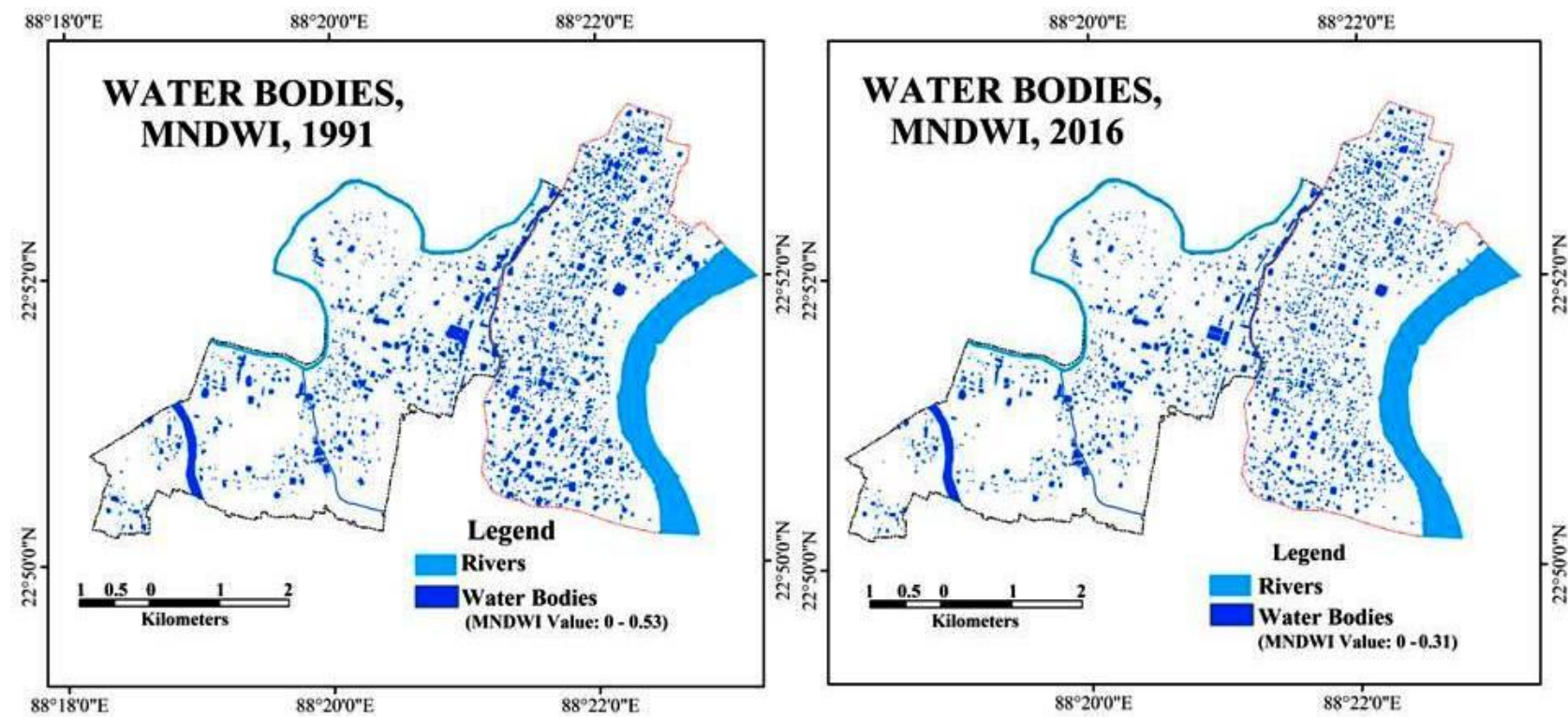

Figure 5: Changes in Water Bodies, 1991 and 2016

Source: Prepared by the Authors

\section{Land Transformation Scenario: Magnitude, Rate and Nature of Changes}

The rate of changes in LULC, the intensity and integrated indices have shown in Table 4. The rate of changes in the urban areas remains higher throughout the study period. It has reached at its maximum in 1996-2001, 2006-11 and 2011-16 periods. Besides, it shows the maximum intensity of change during the first five years (1991-96) of the stipulated period. Changes in green covers were highest in 19962001, whereas minimum alteration is visible in the last phase (2011-16). The transformation of water bodies has taken place at a trivial pace during the stipulated period (1991-2016) though the rate attains highest during the 2011-16 phase. The alteration of wastelands has occurred in an unnoticeable snail's speed over the reviewed periods. The built-up areas exhibit the highest LDI value of 5.06 in 1991-96, followed by 3.50 in 2006-11. On the contrary, the vegetation covers and water bodies reveal the most significant integrated value of 4.20 and 0.16 respectively in 1991-96 interval due to the rapid conversion of green and blue spaces into red space during the phase (Table 4).

\begin{tabular}{|c|c|c|c|c|c|c|c|c|c|c|c|c|c|c|c|}
\hline & \multicolumn{3}{|c|}{$1991-96$} & \multicolumn{3}{|c|}{ 1996-2001 } & \multicolumn{3}{|c|}{ 2001-2006 } & \multicolumn{3}{|c|}{$2006-11$} & \multicolumn{3}{|c|}{ 2011-16 } \\
\hline & $\mathbf{A i}$ & $\mathrm{Ci}$ & LDI & $\mathbf{A i}$ & $\mathrm{Ci}$ & LDI & $\mathbf{A i}$ & $\mathrm{Ci}$ & LDI & $\mathbf{A i}$ & $\mathrm{Ci}$ & LDI & $\mathbf{A i}$ & $\mathrm{Ci}$ & LDI \\
\hline Built-up Area & 0.46 & 0.11 & 5.06 & 0.50 & 0.06 & 3.00 & 0.43 & 0.03 & 1.29 & 0.50 & 0.07 & 3.50 & 0.50 & 0.02 & 1.00 \\
\hline Vegetation Cover & 0.42 & 0.10 & 4.20 & 0.45 & 0.05 & 2.25 & 0.42 & 0.03 & 1.26 & 0.40 & 0.05 & 2.00 & 0.34 & 0.02 & 0.68 \\
\hline Water Body & 0.08 & 0.02 & 0.16 & 0.04 & 0.00 & 0.01 & 0.08 & 0.01 & 0.08 & 0.04 & 0.01 & 0.04 & 0.13 & 0.01 & 0.13 \\
\hline Waste Land & 0.04 & 0.01 & 0.04 & 0.01 & 0.00 & 0.00 & 0.07 & 0.01 & 0.07 & 0.06 & 0.01 & 0.06 & 0.03 & 0.00 & 0.00 \\
\hline
\end{tabular}

\section{Driving Forces}

Along with the gradual increase of urban population, urbanisation is also linked with the transformation of land use, economic activities and cultural attributes. The Chandannagar city has experienced a gradual morphological alteration due to the continuous increase of urban residents since the initiation of the French colonial establishment. The enrichment of trade in the early $18^{\text {th }}$ Century speeds up the urbanisation process, and the city started to expand towards the south (Gondolpara) (Ghosh and Siddique, 2018b). In 1753, the city was inhabited by only 25,722 population ( 6180 families), which had reached to 26,831 in 1901 
(Banerjee, 1972). Thereafter, the population increased persistently in the subsequent decades with wide fluctuations in growth rates. Except for 1901-11 (-5.73\%), all other decades have shown a positive growth rate. In 2011, the city has achieved Class I status by accommodating nearly 166867 urbanites. Indeed, the population of the city has increased almost five times (504\%) over the last 100 years (1901- 2001). This population increment intensifies the development of urban structures with the simultaneous diminishing of green and blue spaces. The growth of urban dwellers shows a significant positive relationship with built-up areas $\left[R^{2}=0.747\right]$ and a moderately inverse correlation with the green $\left[R^{2}=0.470\right]$ and blue spaces $\left[R^{2}=0.353\right]$ for the study period. For example, in the 1991-2001 decade, the higher rate of urbanisation (34.73\%) have increased the built-up spaces at a rate of $47.72 \%$ with a declining $29.21 \%$ vegetation $(29.21 \%)$ and 23.64\% water cover areas.

On the contrary, low population growth during the last decade $(2.89 \%)$ lowers down the alteration rates of LULC classes. The per capita LCR (Hectare/person) increased from 0.006 in 1991 to 0.008 in 2016. Such progressive increase specifies an overall low-density urban growth, which should be considered as an indicator of urban sprawl (Hasse and Lathrop, 2003). The haphazard urban growth undoubtedly affects the spatial composition as a remarkable inverse correlation between the built-up space and vegetated land $\left[R^{2}=0.998\right]$, and water bodies $\left[R^{2}=0.983\right]$ is observed.

\section{Conclusion}

The study reveals that slow but haphazard urban expansion of the city has significantly altered the LULC fabric during the aforementioned period. The existing green and blue spaces may prove inadequate to sustain the city's health. Removal of vegetation cover and water bodies may affect the living condition, biopsychosocial wellbeing and lifestyle of the city dwellers. Hence, a strong need for proper, scientific and practical urban land use planning has been felt to endorse environmental sustainability and to restrain further degradation. The present research may help urban planners as well as the city's authority to adopt long-term planning for the near future.

\section{References}

Bhatta, B. (2009). Analysis of urban growth pattern using Remote Sensing and GIS: A case study of Kolkata, India. International Journal of Remote Sensing, 30 (18), 4733-4746. doi:10.1080/01431160802651967

Banerjee, A. K. (1972). Hoogly District Gazetteers, Calcutta: The Bengal Secretariat Book Depot. Retrieved from http://www.hooghly.gov.in/hooghlygazetweb/i ndex.html

Census of India (2011). Chandannagar City Census 2011 data. Government of India.

Retrieved from https://www.census2011.co.in/census/city/239 -chandannagar.html

Cheruto, M. C., Kauti, M. K., Kisangau, P. D. \& Kariuki, P. (2016). Assessment of land use and land cover change using GIS and Remote Sensing techniques: A case study of Makueni County, Kenya, Journal of Remote Sensing and GIS, 5(4) DOI: $10.4175 / 2469-4134.1000175$

Cohen, B. (2004). Urban growth in developing countries: A review of current trends and a caution regarding existing forecasts. World Development, 32(1), 23-51.

Dewan, A. M., Yamaguchi, Y., \& Rahman, M. Z. (2012). Dynamics of land use/cover changes and the analysis of landscape fragmentation in Dhaka Metropolitan, Bangladesh. GeoJournal, 77, 315-330. doi: 10.1007/s10708-010-9399- x

Fanan, U., Dlama, K. I., \& Olusey, I. O. (2011). Urban expansion and vegetal cover loss in and around Nigeria's Federal Capital City. Journal of Ecology and the Natural Environment, 3(1), 1-10.

Fenta, A. A., Yasuda, H., Haregeweyn, N., Belay, A. S., Hadush, Z., Gebremedhin, A. M., \& Mekonnen, G. (2017). The dynamics of urban expansion and land use/land cover changes using remote sensing and spatial metrics: The case of Mekelle City of Northern Ethiopia. International Journal of Remote Sensing, 38 (14), 
4107-4129.

doi:10.1080/01431161.2017.1317936

Ghosh, S., \& Siddique, G. (2018a). Change detection of built up areas applying built-up index for Chandannagar city. International. Journal of Technogy Research and Management, 5(4), 1-7.

Ghosh, S., \& Siddique, G. (2018b). A dependent city in independent india in Hugli district: Its evolution, expansion and related issues. Online International Interdisciplinary Research Journal, 8(4), 387-398.

Han, J., Hayashi, Y., Cao, X., \& Imura, H. (2009). Application of an integrated system dynamics and cellular automata model for urban growth assessment: A case study of Shanghai, China. Landscape and Urban Planning 91:133-141. doi:10.1016/j.landurbplan.2008.12.002

Haregeweyn, N., Fikadu, G., Tsunekawa, A., Tsubo, M., \& Meshesha, D. T. (2012). The dynamics of urban expansion and its impacts on land use/land cover change and small-scale farmers living near the urban fringe: A case study of Bahir Dar, Ethiopia. Landscape and Urban Planning, $106 \quad$ (2), 149-157. doi:10.1016/j.landurbplan.2012.02.016

Hasse, J. E. \& Lathrop, R. G. (2003). Land resource impact indicators of urban sprawl. Appied Geography, 23 (2), 159-175. doi:10.1016/j.apgeog.2003.08.002.

Jain, M., Dimri, A. P. \& Niyogi, D. (2016). Urban sprawl patterns and processes in Delhi from 1977 to 2014 based on remote sensing and spatial metrics approaches. Earth Interactions, 20, 1-29. doi: 10.1175/EI-D-15-0040.1

Jinlong, C., Jiangang, X. \& Shu, G. (2007). Spatiotemporal characteristics of residential land growth in Hefei of Anhui Province, China. Chinese Geographical Science, 17(2), 135-142. doi: 10.1007/s11769-007-0135-5

Kiggundu, N., Anaba, L. A., Banadda, N., Wanyama, J. \& Kabenge, I. (2018). Assessing land use and land cover changes in the Murchison Bay catchment of Lake Victoria basin in Uganda. Journal of Sustainable Development, 11(1), 4455. doi:10.5539/jsd.v11n1p44
Liu, Z., He, C., Zhou, Y. \& Wu, J. (2014). How much of the World's Land has been Urbanized, Really? A Hierarchical Framework for Avoiding Confusion. Landscape Ecology, 29(5), 763-771. doi:10.1007/s10980-014-0034-y

Lyon, J. G., Yuan, D., Lunetta, R. S. \& Elvidg, C. D. (1998). A change detection experiment using vegetation indices. Photogrammetric Engineering and Remote Sensing, 64 (2), 143150.

Moghadam, H. S. \& Helbich, M. (2013). Spatiotemporal urbanization processes in the megacity of Mumbai, India: A markov chains-cellular automata urban growth model. Applied Geography, 40, 140-149. doi: 10.1016/j.apgeog.2013.01.009

Mohan, M., Pathan, S. K., Narendrareddy, K., Kandya, A., \& Pandey, S. (2011). Dynamics of urbanization and its impact on land use/land cover: A case study of megacity Delhi. Journal of Environmental Protection, 2, 1274-1283.

Mohapatra, S. N., Pani, P. \& Sharma, M. (2014). Rapid urban expansion and its implications on geomorphology: A remote sensing and GIS based study. Geography Journal, 1-10. http://dx.doi.org/10.1155/2014/361459

Mundia, C. N., \& Murayama, Y. (2010). Modeling spatial processes of urban growth in African cities: A case study of Nairobi city. Urban Geography, 31(2), 259-272. doi: 10.2747/02723638.31.2.259

Sahana, M., Hong, H., \& Sajjad, H. (2018). Analyzing urban spatial patterns and trend of urban growth using urban sprawl matrix: A study on Kolkata urban agglomeration, India. Science of the Total Environment, 628-629, 1557-1566. doi:10.1016/j.scitotenv.2018.02.170

Siddique, G., \& Mukherjee, N. (2017). Transformation of agricultural land for urbanisation, infrastructural development and question of future food security: Cases from parts of Hugli district, West Bengal. Space and Culture, India, 5(2), 47-68. doi: 10.20896/saci.v5i2.269

Sharma, L., Pandey, P. C., \& Nathawat. M. S. (2012). Assessment of land consumption rate 
with urban dynamics change using geospatial techniques. Journal of Land Use Science, 7(2), 135-148. doi:10.1080/1747423X.2010.537790.

Thapa, R. B., \& Murayama. Y. (2010). Drivers of urban growth in the Kathmandu valley, Nepal: examining the efficacy of the analytic hierarchy process. Applied Geography, 30 (1), 70-83. doi:10.1016/j.apgeog.2009.10.002.

Tucker, C. J. (1979). Red and photographic infrared linear combinations for monitoring vegetation. Remote Sensing of Environment, 8, 127-150.United Nations Organization (UNO) (2007). World population prospects: The 2006 revision. UN population division database.

Wakode, H. B., Baier, K., Jha, R., \& Azzam, R. (2013). Analysis of urban growth using landsat TM/ETM data and GIS: A case study of Hyderabad, India, Arabian Journal of Geosciences, 7, 109-121. doi:10.1007/s12517013-0843-3

Wu, K., \& Zhang, H. (2012). Land use dynamics built up land expansion patterns and driving forces analysis of the fast-growing Hangzhou metropolitan area, Eastern China (1978-2008). Applied Geography, 34, 137-145.

Xu, G., Jiao, L., Liu, J., Shi, Z., Zeng, C., \& Liu, Y. (2019). Understanding urban expansion combining macro patterns and micro dynamics in three Southeast Asian megacities. Science of the Total Environment, 660, 375-383. doi: 10.1016/j.scitotenv.2019.01.039

$\mathrm{Xu}, \mathrm{H}$. (2006) Modification of Normalised Difference Water Index (NDWI) to enhance open water features in remotely sensed imagery. International Journal of Remote Sensing, 27(14), 3025-3033.

Yang, X., \& Lo, C. P. (2002). Using a time series of satellite imagery to detect land use and land cover changes in the Atlanta, Georgia metropolitan area. International Journal of Remote Sensing, 23(9), 1775-1798.

Yin, J., Yin, Z., Zhong, H., Xu, S., Hu, X., Wang, J., $\& \mathrm{Wu}$, J. (2011). Monitoring urban expansion and land use/land cover changes of Shanghai metropolitan area during the transitional economy (1979-2009) in China. Environmental Monitoring and Assessment, 177(1), 609- 621.

Yuan, F., Sawaya, K. E., Loeffelholz, B. C., \& Bauer, M. E. (2005). Land cover classification and change analysis of the twin cities (Minnesota) metropolitan area by multi-temporal landsat remote sensing. Remote Sensing of Environment, 98(2-3), 317-328. doi: 10.1016/j.rse.2005.08.006

Zha, Y., Gao, J., \& Ni, S., (2003) Use of Normalized Difference Built-up Index in automatically mapping urban areas from TM imagery. International Journal of Remote Sensing, 24, 583-594.

\section{Acknowledgements}

The authors express their gratitude to the anonymous reviewers and the editor for their valuable comments, suggestion and assistance in improvement of the paper.

\section{About the Authors}

Professor Giyasuddin Siddique has been working in the Department of Geography, the University of Burdwan, since 1999. He acquired his Masters degree in Geography in 1983 from University of Burdwan and Ph. D. degree in 1999 from the same University. He has nearly 57 research papers published in various esteemed National and International Journals and he has also written six textbooks. Nine scholars have been awarded PhD and six scholars have been awarded M. Phil. degree under his supervision. Another eight scholars are currently working under his guidance for the fulfilment of a Ph.D. degree. He has more than 30 years' experience of field-based research on forests, tribal culture, human ecology, social environmental problems, river dams, hazard studies, gender issues, human development, quality of life, etc.

Subhendu Ghosh, a Junior Research Fellow (PhD Scholar), has completed M. A. in 2013 and is presently working in the Department of Geography, the University of Burdwan. He has five research papers published in various Journals of National and International repute. He is keenly interested in the study of emerging urban problems. 
Arindam Roy is currently working as a UGC- published in International Journals. He has Junior Research Fellow (PhD Scholar) in the research interest in contemporary urban Department of Geography, the University of phenomena and various other socio-cultural Burdwan since 2016. He has completed M.Sc. issues. from the Department of Geography, University of Calcutta. He has nine research papers 